\title{
A NOTE ON THE LOCATING-TOTAL DOMINATION IN GRAPHS
}

\author{
Mirka Miller (posthumous) \\ School of Mathematical and Physical Sciences \\ University of Newcastle, Australia \\ Department of Mathematics \\ University of West Bohemia, Pilsen, Czech Republic \\ e-mail: mirka.miller@gmail.com \\ R. Sundara Rajan \\ Department of Mathematics, Anna University, Chennai-600 025, India \\ e-mail: vprsundar@gmail.com \\ R. JAYAGOPAL, IndRA RAJASINGH \\ School of Advanced Sciences, VIT University, Chennai-600 12\%, India \\ e-mail: jgopal89@gmail.com \\ indrarajasingh@yahoo.com \\ AND \\ Paul Manuel \\ Department of Information Science, Kuwait University, Safat, Kuwait \\ e-mail: pauldmanuel@gmail.com
}

\begin{abstract}
In this paper we obtain a sharp (improved) lower bound on the locatingtotal domination number of a graph, and show that the decision problem for the locating-total domination is NP-complete.

Keywords: dominating set, total dominating set, locating-dominating set, locating-total dominating set, regular graphs.

2010 Mathematics Subject Classification: 05C69.
\end{abstract}

\section{REFERENCES}


[1] I. Charon, O. Hudry and A. Lobstein, Minimizing the size of an identifying or locating-dominating code in a graph is NP-hard, Theoret. Comput. Sci. 290 (2003) 2109-2120. doi:10.1016/S0304-3975(02)00536-4

[2] M. Chellali, On Locating and differentiating-total domination in trees, Discuss. Math. Graph Theory 28 (2008) 383-392. doi:10.7151/dmgt.1414

[3] X. Chen and M.Y. Sohn, Bounds on the locating-total domination number of a tree, Discrete Appl. Math. 159 (2011) 769-773. doi:10.1016/j.dam.2010.12.025

[4] J.-F. Fang, The bipancycle-connectivity of the hypercube, Inform. Sci. 178 (2008) 4679-4687.

[5] M.R. Garey and D.S. Johnson, Computers and Intractability: A Guide to the Theory of NP-Completeness (W.H. Freeman \& Company Publisher, San Francisco, US, 1979).

[6] T.W. Haynes, M.A. Henning and J. Howard, Locating and total dominating sets in trees, Discrete Appl. Math. 154 (2006) 1293-1300. doi:10.1016/j.dam.2006.01.002

[7] M.A. Henning and C. Löwenstein, Locating-total domination in claw-free cubic graphs, Discrete Math. 312 (2012) 3107-3116. doi:10.1016/j.disc.2012.06.024

[8] M.A. Henning and N.J. Rad, Locating-total domination in graphs, Discrete Appl. Math. 160 (2012) 1986-1993. doi:10.1016/j.dam.2012.04.004

[9] H. Hosoya and F. Harary, On the matching properties of three fence graphs, J. Math. Chem. 12 (1993) 211-218. doi:10.1007/BF01164636

[10] B.N. Omamalin, Locating total dominating sets in the join, corona and composition of graphs, Appl. Math. Sci. 8 (2014) 2363-2374. doi:10.12988/ams.2014.43205

[11] P.J. Slater, Fault-tolerant locating-dominating sets, Discrete Math. 249 (2002) 179-189. doi:10.1016/S0012-365X(01)00244-8

[12] J. Xu, Topological Structure and Analysis of Interconnection Networks (Kluwer Academic Publishers, London, UK, 2001). doi:10.1007/978-1-4757-3387-7

Received 6 January 2016

Revised 20 June 2016

Accepted 20 June 2016 